\title{
Prediction accuracies and genetic parameters for test-day traits from genomic and pedigree-based random regression models with or without heat stress interactions
}

\author{
M. Bohlouli, ${ }^{1}$ S. Alijani, ${ }^{2}$ S. Naderi, ${ }^{1}$ T. Yin, ${ }^{1}$ and S. König ${ }^{1 *}$ \\ ${ }^{1}$ Institute of Animal Breeding and Genetics, Justus-Liebig-University Gießen, 35390 Gießen, Germany \\ ${ }^{2}$ Department of Animal Science, University of Tabriz, 51666 Tabriz, East Azarbaijan, Iran
}

\begin{abstract}
The aim of this study was to compare genetic (co)variance components and prediction accuracies of breeding values from genomic random regression models (gRRM) and pedigree-based random regression models (pRRM), both defined with or without an additional environmental gradient. The used gradient was a temperaturehumidity index (THI), considered in statistical models to investigate possible genotype by environment $(\mathrm{G} \times \mathrm{E})$ interactions. Data included 106,505 test-day records for milk yield (MY) and 106,274 test-day records for somatic cell score (SCS) from 12,331 genotyped Holstein Friesian daughters of 522 genotyped sires. After single nucleotide polymorphism quality control, all genotyped animals had 40,468 single nucleotide polymorphism markers. Test-day traits from recording years 2010 to 2015 were merged with temperature and humidity data from the nearest weather station. In this regard, 58 large-scale farms from the German federal states of Berlin-Brandenburg and Mecklenburg-West Pomerania were allocated to 31 weather stations. For models with a THI gradient, additive genetic variances and heritabilities for MY showed larger fluctuations in dependency of DIM and THI than for SCS. For both traits, heritabilities were smaller from the gRRM compared with estimates from the pRRM. Milk yield showed considerably larger $\mathrm{G} \times \mathrm{E}$ interactions than SCS. In genomic models including a THI gradient, genetic correlations between different DIM $\times$ THI combinations ranged from 0.26 to 0.94 for MY. For SCS, the lowest genetic correlation was 0.78 , estimated between SCS from the last DIM class and the highest THI class. In addition, for THI $\times$ THI combinations, genetic correlations were smaller for MY compared with SCS. A 5-fold cross-validation was
\end{abstract}

Received July 5, 2018.

Accepted September 6, 2018.

*Corresponding author: sven.koenig@agrar.uni-giessen.de used to assess prediction accuracies from 4 different models. The 4 different models were gRRM and pRRM, both modeled with or without $\mathrm{G} \times \mathrm{E}$ interactions. Prediction accuracy was the correlation between breeding values for the prediction data set (i.e., excluding the phenotypic records from this data set) with respective breeding values considering all phenotypic information. Prediction accuracies for sires and for their daughters were largest for the gRRM considering $\mathrm{G} \times \mathrm{E}$ interactions. Such modeling with 2 covariates, DIM and THI, also allowed accurate predictions of genetic values at specific DIM. In comparison with a pRRM, the effect of a gRRM with $\mathrm{G} \times \mathrm{E}$ interactions on gain in prediction accuracies was stronger for daughters than for sires. In conclusion, we found stronger effect of THI alterations on genetic parameter estimates for MY than for SCS. Hence, gRRM considering THI especially contributed to gain in prediction accuracies for MY.

Key words: genotype by environment interaction, temperature-humidity index, random regression model, genomic prediction

\section{INTRODUCTION}

In the global dairy cattle industry, daughter records of bulls are available in various environments and countries because of the widespread use of AI. Environmental differences might contribute to daughter record variations, consequently resulting in re-rankings of bulls across environments (Hammami et al., 2009; Hayes et al., 2016). These are the principles of a genotype by environment $(\mathbf{G} \times \mathbf{E})$ interaction, meaning that different genotypes react differently across environments (Falconer and Mackay, 1996). Generally, in quantitative genetic studies, a genetic correlation lower than 0.80 between the same trait measured in 2 discrete environments indicates $\mathrm{G} \times \mathrm{E}$ interaction (Robertson, 1959). Challenging environmental impact, especially climate change and associated heat stress response, might cause re-rankings of sires under different climatic conditions. 
As a consequence, to be competitive in a broad range of climates worldwide, international dairy cattle breeding programs should consider $\mathrm{G} \times \mathrm{E}$ interaction effects in genetic evaluations (Ravagnolo and Misztal, 2000). Some countries (e.g., Australia) routinely implement genomic and genetic evaluations for heat tolerance (Nguyen et al., 2018).

In the past decade, several studies analyzed $\mathrm{G} \times \mathrm{E}$ interactions for milk production traits using either pedigree-based relationship matrices (pRRM; Calus et al., 2006; Hammami et al., 2013; Carabaño et al., 2016) or genomic relationship matrices (gRRM; HaileMariam et al., 2015; Tiezzi et al., 2017). To quantify differences in gene expressions in various environments, genomic multiple-trait models (Haile-Mariam et al., 2015; Yao et al., 2017) and reaction norm or random regression models (RRM; Macciotta et al., 2017; Tiezzi et al., 2017) were applied. Yao et al. (2017) and Tiezzi et al. (2017) demonstrated the advantages of statistical models with interaction effects for the estimation of environment-specific genomic parameters. Accordingly, also in simulations, genomic predictions had improved accuracies when considering specific QTL in different environments (Bohlouli et al., 2017).

Random regression models allow the estimation of genetic (co)variance components and breeding values over the whole trajectory of a time-dependent (e.g., DIM) or environment-dependent (e.g., temperaturehumidity indices; THI) covariate. Modeling the effect of a genotype as a function of time and environment (Bohmanova et al., 2007; Brügemann et al., 2011) implies the detection of $\mathrm{G} \times \mathrm{E}$ interactions via differences in genetic (co)variance components for different combinations of DIM with THI. In this regard, Ravagnolo and Misztal (2000) found considerable genetic variances for heat tolerance when applying an RRM to production traits and including a function for THI. Furthermore, specific genetic parameters or breeding values for distinct heat stress levels (Brügemann et al., 2011; Nguyen et al., 2016) are suitable indicators for the selection of optimal progeny testing environments (Schierenbeck et al., 2011) or for the selection of herds to be included in cow training sets for genomic selection (Naderi et al., 2018). However, the effect of THI combined with a large data set of genotyped cows from commercial large-scale production herds on possible $\mathrm{G} \times \mathrm{E}$ interactions, and on accuracies of genomic predictions, needs deeper analyses. Therefore, the objective of the present study was to apply RRM with gRRM and pRRM and to study the effect of models with THI gradients on (1) estimates for genetic (co)variance components, (2) possible $\mathrm{G} \times \mathrm{E}$ interactions, and (3) accuracies of genomic predictions.

\section{MATERIALS AND METHODS}

\section{Phenotypes}

Data were first-lactation test-day records for milk yield (MY) and SCC (recording years 2010-2015) from 12,331 genotyped Holstein dairy cows kept in 58 largescale test herds. Herds were located in the region of former East Germany (i.e., in the federal states of Berlin-Brandenburg and Mecklenburg-Western Pomerania). Age at first calving ranged from 20 to 39 mo. Days in milk were restricted between 5 and 305 d. Each cow had at least 5 test-day records, and a minimum of 5 records were defined for each herd test-date. Test-day SCC was transformed to SCS by SCS $=\log _{2}\left(\frac{\mathrm{SCC}}{100,000}\right)+4$. A constant 4 was added to avoid the problem of negative values in the data (Martins et al., 2011). After data editing, 106,274 test-day records were available for SCS and 106,505 test-day records were available for MY. The SCS ranged from 0.16 to 10.47 , and MY ranged from 2.0 to $61.5 \mathrm{~kg}$.

\section{Genotypes and Pedigrees}

A total of 5,104 animals, including 4,973 cows and 131 sires, were genotyped with the Illumina BovineSNP50 v2 BeadChip (Illumina, San Diego, CA). A further set of 7,749 animals, including 7,358 cows and 391 sires, were genotyped with the Illumina Bovine Eurogenomics $10 \mathrm{~K}$ low-density chip (the so-called Euro10K LD chip; see Reents, 2014). The animals genotyped with $10 \mathrm{~K}$ were further imputed to $50 \mathrm{~K}$ using the procedure for official national genetic evaluations as implemented by project partner VIT Verden (Segelke et al., 2012). After imputation, 45,613 SNP were available from 522 genotyped sires and 12,331 genotyped cows. The SNP quality controls were performed using the preGSf90 program (Aguilar et al., 2010). First, we discarded 3,581 SNP with minor allele frequency lower than 0.05 . According to Wiggans et al. (2009), a difference between observed and expected heterozygous frequencies larger than 0.15 indicates a departure from Hardy-Weinberg equilibrium. In this regard, we excluded 2 SNP from the ongoing analyses. Furthermore, according to Wiggans et al. (2009), we discarded 696 highly correlated SNP and 866 SNP located on the X and Y chromosomes. Finally, 40,468 SNP were considered for all genomic analyses.

Pedigree was traced back as far as possible (back to founders born in 1965) to increase across-herds genetic connectedness. The pedigree file included 48,977 animals (i.e., 3,085 sires and 33,703 dams). Among the 
Table 1. Pedigree structure

\begin{tabular}{lcc}
\hline Information source & $\begin{array}{c}\text { Total } \\
\text { no. }\end{array}$ & $\begin{array}{c}\text { Genotyped } \\
\text { no. }\end{array}$ \\
\hline Animal from pedigree data & 48,977 & 12,853 \\
Sire from pedigree data & 3,085 & 522 \\
Dam from pedigree data & 33,703 & 134 \\
Cows with phenotypes & 12,331 & 12,331 \\
With genotyped sires & & 11,448 \\
With genotyped dams & & 151 \\
\hline
\end{tabular}

sires, 250 sires (202 with genotypes) had 1 to 4 genotyped daughters, 305 sires (274 with genotypes) had 5 to 50 genotyped daughters, 33 sires (31 with genotypes) had 51 to 100 genotyped daughters, and 17 sires (15 with genotypes) had more than 100 genotyped daughters. One genotyped sire had 772 genotyped daughters. Only 134 dams were genotyped. Detailed information for animals with phenotypes and genotypes is given in Table 1.

\section{Meteorological Data}

The weather station nearest to the farm was identified using longitude and latitude information of farms and weather stations and applying the Geosphere package in R (Hijmans et al., 2016). In this regard, 31 different weather stations were allocated to the 56 different farms. The maximum distance between a weather station and a farm was $32.8 \mathrm{~km}$, and the minimum distance was $1.2 \mathrm{~km}$. Hourly THI was calculated based on hourly temperature (T) and hourly relative humidity $(\mathrm{RH})$ as follows (NRC, 1971):

$\mathrm{THI}=(1.8 \times \mathrm{T}+32)-(0.55-0.0055 \times \mathrm{RH}) \times(1.8 \times \mathrm{T}-26)$.

The average THI $3 \mathrm{~d}$ before the test date was merged with the respective test-day record (Bohmanova et al., 2008).

\section{Statistical Models}

Genomic RRM for MY and SCS considered only the time-dependent covariate DIM (model 1) or DIM and THI simultaneously (model 2). The gRRM (Equation 1) was

$$
\begin{aligned}
& y_{i j k l m n}=\mathrm{HTD}_{i}+\mathrm{MF}_{j}+\sum_{o=1}^{q} \alpha_{k o} \mathbf{z}_{o}(d)+\sum_{o=1}^{q} \beta_{l o} \mathbf{z}_{o}(d) \\
& +\sum_{o=1}^{q} \gamma_{m o} \mathbf{z}_{o}(d)+e_{i j k l m n}
\end{aligned}
$$

and the gRRM (Equation 2) was

$$
\begin{aligned}
& y_{i j k l m n}=\mathrm{HTD}_{i}+\mathrm{MF}_{j}+\sum_{o=1}^{q} \alpha_{k o} \mathbf{z}_{o}(d)+\sum_{o=1}^{q} \beta_{l o} \mathbf{z}_{o}(d) \\
& +\sum_{o=1}^{q} \gamma_{m o} \mathbf{z}_{o}(d)+\sum_{o=1}^{q} \delta_{l o} \mathbf{z}_{o}(t)+\sum_{o=1}^{q} \varepsilon_{m o} \mathbf{z}_{o}(t)+e_{i j k l m n},
\end{aligned}
$$

where $y_{i j k l m n}$ was the $n$th test-day record for the $m$ th cow; $\mathrm{HTD}_{i}$ was a fixed effect for the $i$ th herd test-date, $\mathrm{MF}_{j}$ was a fixed effect for the $j$ th milking frequency ( 2 or 3 times per day, or milking robot); $\alpha_{k o}$ was the oth fixed regression coefficient specific for the $k$ th age at first calving class ( $k=20$ classes; minimum: 20 mo, maximum: $39 \mathrm{mo}$ ) within DIM classes (DIM were grouped into 30 classes: 5-15 d, 16-25 d, . . ., 296-305 d); $\beta_{l o}$ and $\delta_{l o}$ were the oth random regression coefficients for additive genetic effects for the th animal by DIM classes and by THI classes, respectively (THI was grouped into 13 classes: 35-44, 45-46, 47-48, . . ., 67-68); $\gamma_{m o}$ and $\varepsilon_{m o}$ were the oth random regression coefficient for the permanent environmental effects for the $m$ th cow by DIM and by THI classes, respectively; $q$ was the number of covariates; $\mathbf{z}_{o}(d)$ was the vectors of covariates of size $q$ describing the shape of the lactation curve for fixed and random regressions evaluated at the $d$ th DIM class; $\mathbf{z}_{o}(t)$ was the vector of covariates of size $q$ describing the shape of the lactation curve of fixed and random regressions at the th THI class; and $e_{i j k l m n}$ was the random residual effect. The classification of DIM and THI values was done to reduce computation time. Fixed and random regressions were modeled using Legendre polynomials of order 2.

The (co)variance structure for model 1 was

$$
r\left[\begin{array}{c}
\beta \\
\gamma \\
e
\end{array}\right]=\left[\begin{array}{ccc}
\mathbf{H} \otimes \mathbf{W}_{\beta} & 0 & 0 \\
0 & \mathbf{I}_{m} \otimes \mathbf{P}_{\gamma} & 0 \\
0 & 0 & \mathbf{I}_{n} \sigma_{e}^{2}
\end{array}\right]
$$

and the (co)variance structure for model 2 was

$$
\operatorname{Var}\left[\begin{array}{c}
\beta \\
\delta \\
\gamma \\
\varepsilon \\
e
\end{array}\right]=\left[\begin{array}{ccccc}
\mathbf{H} \otimes \mathbf{W}_{\beta} & \mathbf{H} \otimes \mathbf{W}_{\beta \delta} & 0 & 0 & 0 \\
\mathbf{H} \otimes \mathbf{W}_{\delta \beta} & \mathbf{H} \otimes \mathbf{W}_{\delta} & 0 & 0 & 0 \\
0 & 0 & \mathbf{I}_{m} \otimes \mathbf{P}_{\gamma} & \mathbf{I}_{m} \otimes \mathbf{P}_{\gamma \varepsilon} & 0 \\
0 & 0 & \mathbf{I}_{m} \otimes \mathbf{P}_{\varepsilon \gamma} & \mathbf{I}_{m} \otimes \mathbf{P}_{\varepsilon} & 0 \\
0 & 0 & 0 & 0 & \mathbf{I}_{n} \sigma_{e}^{2}
\end{array}\right],
$$

where $\mathbf{W}_{\beta}$ and $\mathbf{W}_{\delta}$ were $3 \times 3$ (co)variance matrices of random regression coefficients for the additive genetic effects by DIM and THI classes, respectively; $\mathbf{W}_{\beta \delta}$ and $\mathbf{W}_{\delta \beta}$ were $3 \times 3$ covariance matrices for the additive 
genetic effects for combinations of DIM and THI classes, respectively; $\mathbf{P}_{\gamma}$ and $\mathbf{P}_{\varepsilon}$ were $3 \times 3$ (co)variance matrices of random regression coefficients for permanent environmental effects by DIM and THI, respectively; $\mathbf{P}_{\gamma \varepsilon}$ and $\mathbf{P}_{\varepsilon \gamma}$ were $3 \times 3$ covariance matrices for permanent environmental effects for combinations of DIM and THI classes, respectively; $\otimes$ denotes the Kronecker product of matrices; $\sigma_{e}^{2}$ was the residual variance; and $\mathbf{I}_{m}$ and $\mathbf{I}_{n}$ were identity matrices for permanent environmental effects considering $m$ cows and residual effects considering $n$ observations, respectively.

In single-step genomic best linear unbiased prediction models as developed by Aguilar et al. (2010), the matrix $\mathbf{H}$ combines the pedigree-based numerator relationship matrix $\mathbf{A}$ with the genomic relationship matrix $\mathbf{G}$ to consider animals with and without genomic information simultaneously. The inverse of $\mathbf{H}$ was defined as

$$
\mathbf{H}^{-1}=\mathbf{A}^{-1}+\left[\begin{array}{cc}
0 & 0 \\
0 & \mathbf{G}^{-1}-\mathbf{A}_{22}^{-1}
\end{array}\right] .
$$

The $\mathbf{G}$ matrix was constructed according to VanRaden (2008).

In the pRRM, the pedigree-based relationship matrix A was used instead of the $\mathbf{H}$ matrix. Hence, model 3 was a pRRM in analogy to model 1 , just considering the continuous DIM effect. Model 4 was a pRRM in analogy to model 2 (i.e., considering both effects DIM and THI). All analyses were conducted using the GIBBS2F90 program from the BLUPF90 software package (Misztal et al., 2002) using a Bayesian framework via Gibbs sampling. In total, 60,000 samples were generated, and the first 10,000 samples were discarded as burn-in. Posterior means and standard deviations of (co)variance components were calculated from every 50th sample. The number of samples and the length of the burn-in period were determined based on visual inspections for all estimates.

\section{Estimation of Genetic Parameters}

The additive genetic and permanent environmental (co)variances matrices were calculated as $\mathbf{\Phi} \mathbf{W} \boldsymbol{\Phi}^{\prime}$ and $\mathbf{\Phi} \mathbf{P} \boldsymbol{\Phi}^{\prime}$, respectively, where $\boldsymbol{\Phi}$ was a matrix of Legendre polynomial functions for DIM or THI classes. The elements on the diagonals were additive genetic $\left(\sigma_{a}^{2}\right)$ and permanent environmental $\left(\sigma_{p e}^{2}\right)$ variances for each DIM or THI class. The covariances between the ith DIM and $j$ th THI classes were calculated as $\boldsymbol{\Phi}_{i} \mathbf{W}_{\beta \delta} \boldsymbol{\Phi}^{\prime}{ }_{j}$ and $\boldsymbol{\Phi}_{i} \mathbf{P}_{\gamma \varepsilon} \boldsymbol{\Phi}^{\prime}{ }_{j}$ for additive genetic and permanent environmental effects, respectively. As a consequence, the MY or SCS heritability for the $i$ th DIM class within the $j$ th THI class $\left(h_{(i j)}^{2}\right)$ was

$h_{(i j)}^{2}=\frac{\sigma_{a \beta(i)}^{2}+\sigma_{a \delta(j)}^{2}+2 \sigma_{a \beta \delta(i j)}}{\sigma_{a \beta(i)}^{2}+\sigma_{a \delta(j)}^{2}+2 \sigma_{a \beta \delta(i j)}+\sigma_{p \gamma(i)}^{2}+\sigma_{p \varepsilon(j)}^{2}+2 \sigma_{p \gamma \varepsilon(i j)}+\sigma_{e}^{2}}$,

where $\sigma_{a \beta(i)}^{2}$ and $\sigma_{a \delta(j)}^{2}$ were additive genetic variances for MY or SCS from the $i$ th DIM and $j$ th THI classes, respectively; $\sigma_{p \gamma(i)}^{2}$ and $\sigma_{p \varepsilon(j)}^{2}$ were permanent environmental variances for MY or SCS from the $i$ th DIM and $j$ th THI classes, respectively; $\sigma_{a \beta \delta(i j)}$ and $\sigma_{p \gamma \varepsilon(i j)}$ were additive genetic and permanent environmental covariances for MY or SCS between the $i$ th and $j$ th classes of DIM and THI, respectively; and $\sigma_{e}^{2}$ was the residual variance for MY or SCS. Further model improvement might be due to the consideration of heterogeneous residual variances. However, such modeling implies longer computation time (e.g., Lillehammer et al., 2009). Furthermore, in a comprehensive study by Fujii and Suzuki (2006), modeling of heterogeneous residual variances over years did not affect the ranking of Japanese Holstein sires.

Random regression coefficient solutions were used to estimate genomic breeding values (GEBV) for specific DIM and THI classes. The sum of all GEBV for each individual across DIM or THI classes was the total GEBV for the first lactation $\left(\mathbf{G E B V}_{\text {DIM }}\right)$ or for the whole THI range $\left(\mathbf{G E B V}_{\text {THI }}\right)$, respectively. Accordingly, the conventional EBV based on the pedigree relationship matrix for the first whole lactation was $\mathrm{EBV}_{\text {DIM }}$, and the EBV for the whole THI range was $\mathrm{EBV}_{\mathrm{THI}}$.

\section{Validation of Genomic and Pedigree- Based Predictions}

A 5-fold cross-validation as introduced by Ovenden et al. (2018) was used to compare prediction accuracies from gRRM and pRRM with or without modeling the $\mathrm{G} \times \mathrm{E}$ interactions. For cross-validations, sires were randomly allocated to 5 different groups. Daughter records of sires from 4 groups were used as a training set, and records from remaining daughters from group 5 were considered as a validation set (Figure 1). Daughter group allocations according to the sire information was done to minimize genetic relationships among groups. In the basic runs for all models, GEBV or EBV for all animals were estimated considering the phenotypes from all cows in all groups. In the ongoing run, phenotypes from cows in group 5 (validation set) were discarded. For each model, the prediction accuracy was 


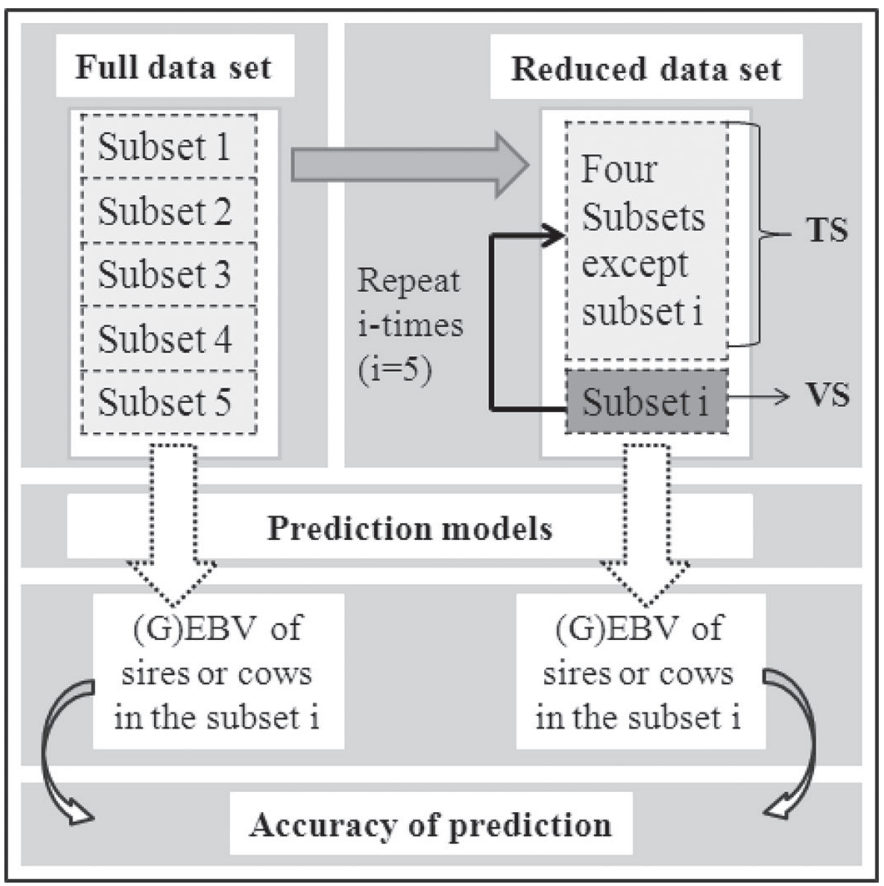

Figure 1. Strategy for the creation of training (TS) and validation (VS) sets and the estimation of prediction accuracy. GEBV = genomic breeding value.

the correlation between breeding values for sires and daughters in the validation set from the reduced data (i.e., without cow phenotypes in group 5) with breeding values for corresponding sires and daughters in the full data set (considering the phenotypes from cows in group 5). Finally, the average prediction accuracy from 5 replicates was calculated.

\section{RESULTS AND DISCUSSION}

\section{Meteorological Data and Traits}

Average monthly temperatures, relative humidity, and THI from 2010 to 2015 are shown in Figure 2. Monthly temperatures and THI were lowest in the winter season (December-February) and highest during the summer months (June-August). Over 6 yr, there was a general increase in monthly mean temperature and THI, especially for winter months. Relative humidity was quite constant in the considered time span. In total, $9.94 \%$ of test-day records matched with THI values larger than 62, indicating heat stress for dairy cows in Europe (Hammami et al., 2015).

Milk yield was highest $(32.87 \mathrm{~kg}$ ) for the DIM class considering DIM 56 to 65 and lowest $(25.82 \mathrm{~kg})$ at the end of lactation for DIM 296 to 305. The maximal SCS (4.24) was identified at the beginning of lactation. The antagonistic relationship between MY and SCS, espe- cially in early lactation, is in line with studies by, for example, de los Campos et al. (2006) or Jamrozik et al. (2010). For all lactation stages, MY was quite constant until THI 62. Afterward, for larger THI, MY decreased significantly. Test-day SCS continuously increased with increasing THI, especially in the early-lactation period. Results correspond with previous evaluations of THI effects on production traits in middle Europe (Hammami et al., 2013, 2015).

\section{Genetic Parameters}

Models Without $G \times E$ Interactions. Heritabilities from model 1 and model 3 for specific DIM classes are shown in Figure 3. As expected, heritabilities for MY were larger than heritabilities for SCS. Heritabilities for MY from model 1 were lowest in the early lactation stage and increased gradually to 0.35 at the end of lactation. Generally, for MY, heritabilities from the pedigree-based model 3 ( 0.20 to 0.46 from early to late lactation, respectively) were larger than heritabilities (0.19 to 0.35 from early to late lactation, respectively) from the genomic model 1. Accordingly, inflated heritabilities at the peripheries of lactations were reported in previous pRRM applications (Strabel et al., 2005; Zavadilová et al., 2005). Heritabilities for SCS were quite constant throughout lactation and ranged between 0.07 and 0.09 from model 1 and between 0.08 and 0.09 from model 3. Heritabilities by DIM from the pRRM without $\mathrm{G} \times \mathrm{E}$ interaction effect (i.e., model 3) were in line with estimates from previous studies (Zavadilová et al., 2005; Nishiura et al., 2015). Posterior standard deviation from model 1 ( $<0.01$ for both traits across DIM) were smaller than from model 3 (range from 0.01 to 0.04 for both traits across DIM), indicating a larger accuracy for variance component estimations when considering the genomic relationship matrix (Bérénos et al., 2014).

Models with $G \times E$ Interactions. Model 2 and model 4 allowed the estimation of (co)variance components for all combinations of THI $\times$ THI and THI $\times$ DIM classes. Genetic parameters from models 2 and 4 for MY and for SCS are presented in Figures 4 and 5, respectively, for the different class combinations. Additive genetic variances for both traits MY (Figure 4A) and SCS (Figure 5A) varied across different combinations of DIM $\times$ THI classes. Hence, additive genetic variances depended on the environmental gradient (i.e., THI) as well as on time alterations (i.e., DIM). Using model 2, the largest additive genetic variance for MY was estimated for the DIM class latest in lactation (296-305 d) combined with the lowest THI class (THI $>45$ ). In contrast, for SCS and model 2, the largest additive genetic variance was identified for the last DIM 


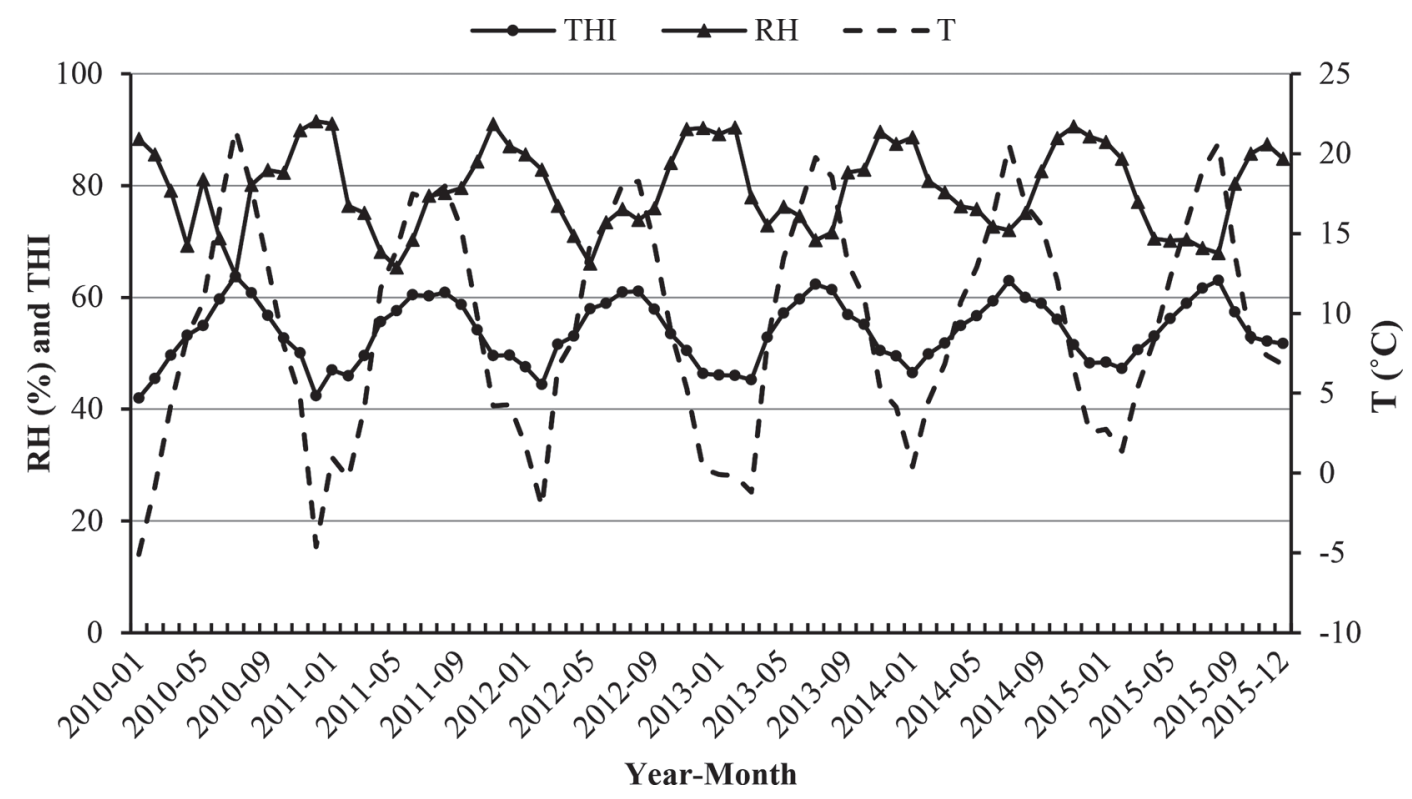

Figure 2. The monthly average temperature-humidity index (THI), relative humidity (RH), and temperature (T) from 2010 to 2015.

class combined with the highest THI class (THI 67-68). Hence, we postulate that dairy cows express their genetic potential differently for a production trait (MY) and for a low-heritability functional trait (SCS) under heat stress conditions. Similarly, in such context, Schierenbeck et al. (2011) analyzed daughter yield deviations and identified a better genetic differentiation for SCS in challenging environments. In contrast, for MY, superior management, husbandry, and feeding conditions in large-scale herds contributed to a broader range of yield deviations and to more extreme sire breeding values (Schierenbeck et al., 2011). Accordingly, König et al. (2005) found an increase of additive-genetic variances for protein yield with increasing herd size. They stated, "A reason for this could be that within herd correlations of genotype $\times$ management (e.g., as arising from feeding according to the genetic potential) are higher in large farms since all available management tools can be applied which would not be feasible on a small farm."

Permanent environmental variances were largest in the late-lactation stage combined with the highest THI class (i.e., THI 67-68) for both traits MY (Figure 4B) and SCS (Figure 5B). Very similar permanent environmental variances were estimated from models 2 and 4 .

For the genomic and pedigree-based models, heritabilities for MY increased by DIM and decreased by THI (Figure 4C). Zwald et al. (2003) focused for herd grouping on several environmental descriptors across country borders. In agreement with results from our study, heritabilities for MY based on data from herds located in hot climates were smaller than heritabilities from herds located in temperate climates. For Brazilian Holstein dairy cattle, Santana et al. (2017) reported the largest production trait heritabilities for low THI values in late lactation. However, they identified opposite heritability trends for SCS. In our study, SCS heritabilities from model 2 and 4 increased with increasing THI at the beginning of lactation but decreased in the late lactation stage (Figure $5 \mathrm{C}$ ). In the studies by Brügemann et al. (2011) and Bohlouli et al. (2013), protein yield and MY heritabilities slightly altered across THI. Differences in additive genetic variances and heritabilities indicate variation in selection response, additionally depending on the function used for modeling both descriptors DIM and THI. Heritabilities for production traits as a function of THI are different depending on populations and locations (e.g., Ravagnolo and Misztal, 2000; Hammami et al., 2015). Santana et al. (2017) expected the largest selection response for MY in the thermal comfort zone because of the largest MY heritabilities for THI $<45$. In our study, heritabilities for SCS increased with increasing THI. Accuracy of selection depends on trait heritabilities. Hence, selection response for SCS might increase when considering trait recording in challenging environments (i.e., environments representing heat stress).

When comparing models with or without $\mathrm{G} \times \mathrm{E}$ interactions, heritabilities were larger from models considering the THI component. Accordingly, Abdullahpour et al. (2013) reported significantly larger heritabilities from models considering detailed environmental herd information. In simulations neglecting the $\mathrm{G} \times \mathrm{E}$ interaction, the residual variance component substantially increased, with effect on heritability decreased 
(Bohlouli et al., 2013). König et al. (2005) identified smaller permanent and residual variance components in small-scale farms than in large-scale farms. This might be due to the heterogeneous environmental effects in large-scale farms, mainly due to specific feeding and management strategies in created subgroups of cows within herds. Inclusion of the source of variation as a $\mathrm{G} \times \mathrm{E}$ interaction component into statistical modeling might increase the additive genetic variance for the trait of interest while simultaneously decreasing the residual effect (Bowman, 1972).

Smaller heritabilities were estimated when using a gRRM (models 1 and 2) instead of a pRRM (models 3 and 4). For a chicken population, Momen et al. (2017) also reported smaller heritabilities for body measurement and productivity when modeling a genomic relationship matrix. Veerkamp et al. (2011) estimated heritabilities for MY, DMI, and BW of Holstein dairy cattle. Estimates were smaller when considering the genomic relationships. Different (co)variance components from $\mathrm{pRRM}$ and gRRM can be expected because for genotyped animals, identity by state relationships and undefined base population structure is used instead of identity by descent relationships (Powell et al., 2010). Snelling et al. (2009) reported that different SNP densities as used for the construction of $\mathbf{G}$ matrices might contribute to differences in variance component estimates. Moreover, some of the environmental effects might be confounded with pedigree relationships (Lee et al., 2010; Veerkamp et al., 2011). The given arguments might explain heritability differences from the pRRM and the gRRM.

Figure 4D (for MY) and Figure 5D (for SCS) display genetic correlations between all combinations of DIM $\times$ THI classes from models 2 and 4 . For model 2 and MY, the genetic correlation was smallest $(0.26)$ between DIM 5 to 15 and THI $<45$, indicating differences in genetic mechanisms for early lactation and for low THI. Early lactation with a natural energy deficiency in high-yielding cows is associated with physiological stress, but THI $<45$ implies well-being for cows. Accordingly, substantial re-rankings of sires according to GEBV for MY were observed; sires with high GEBV early in lactation had low GEBV for THI $<45$ and vice versa (Figure 6). The same tendencies were found in previous studies using pedigree-based relationship matrices to depict DIM $\times$ THI interactions (e.g., Bohlouli et al., 2013; Hammami et al., 2015). Large genetic correlations $(>0.80)$ between MY from the middle of lactation with MY from all THI classes suggest selection of sires with high genetic values at DIM 100 to 200, to use correlated selection response for heat tolerance. For SCS, the lowest genetic correlation (0.78) was estimated between the latest DIM and the highest THI class (Figure 5D). Hence, there was no evidence for the existence of a significant lactation period

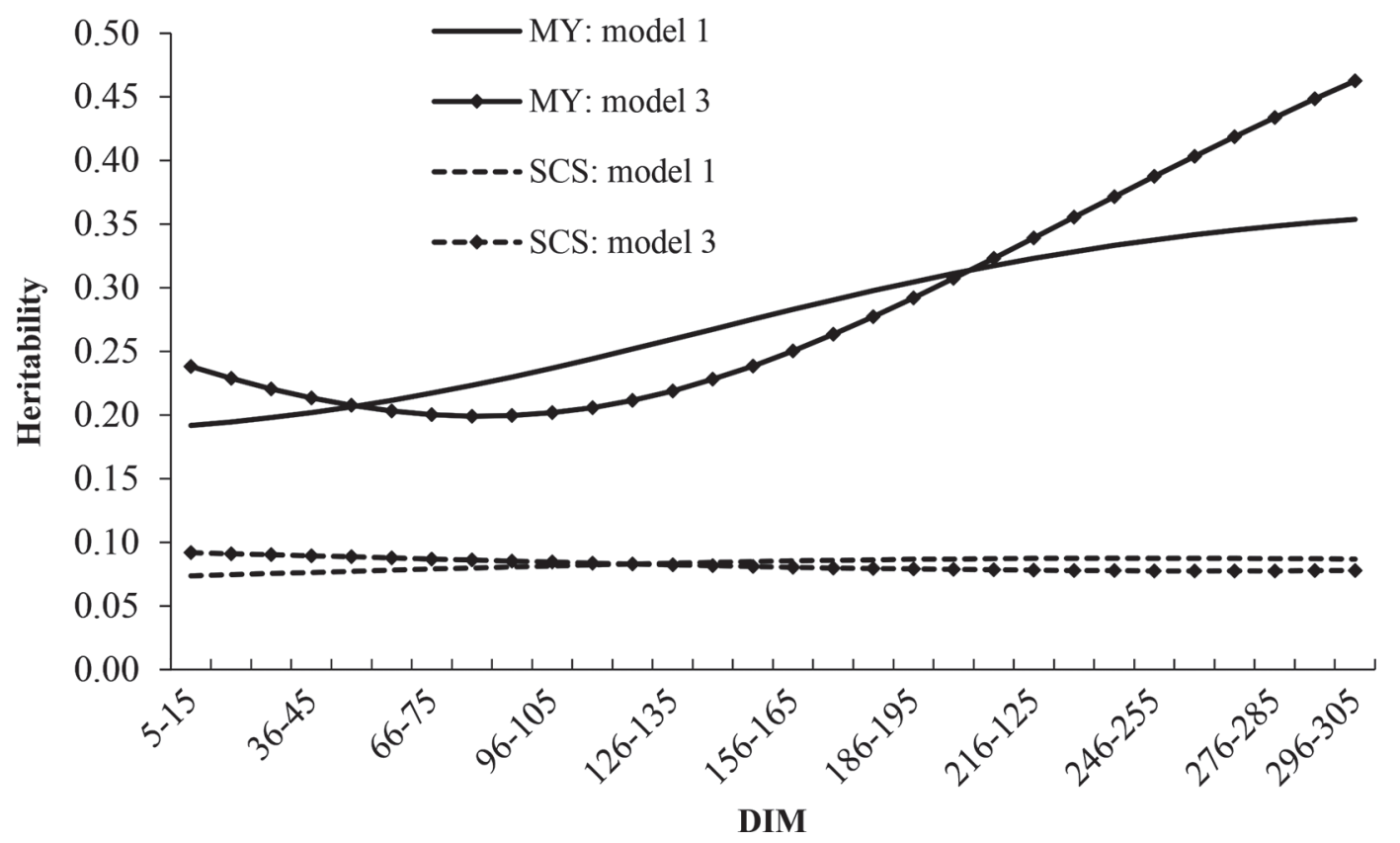

Figure 3. Heritability estimates for milk yield (MY) and SCS for different DIM classes estimated with the genomic random regression model 1 and the pedigree-based random regression model 3 (both models without genotype by environment interactions). For MY, posterior SD of heritabilities ranged from 0.011 to 0.014 for model 1 and from 0.027 to 0.041 for model 3. For SCS, posterior SD of heritabilities ranged from 0.007 to 0.008 for model 1 and from 0.011 to 0.014 for model 3 . 

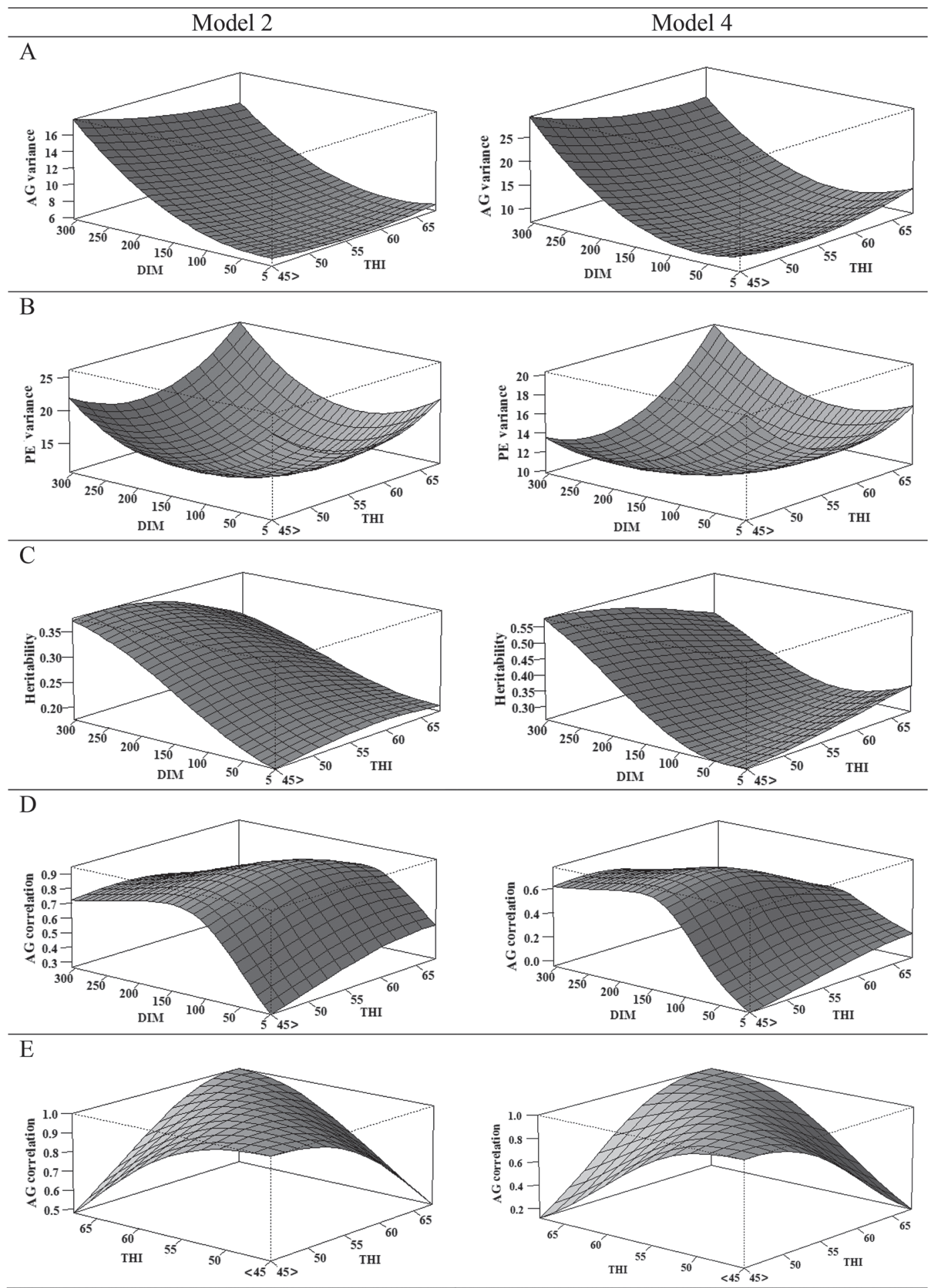

Figure 4. Additive genetic (AG) and permanent environmental (PE) variances, heritabilities, and genetic correlations for milk yield (MY) estimated with the genomic random regression model 2 and the pedigree-based random regression model 4 (both models considering genotype by environment interactions) for DIM and temperature-humidity index (THI) combinations. Posterior SD for estimates from model 2 ranged from 0.32 to 0.95 (A), 0.20 to 0.71 (B), 0.01 to 0.02 (C), 0.03 to 0.08 (D), and 0.00 to 0.07 (E). Posterior SD for estimates from model 4 ranged from 0.68 to $2.62(\mathrm{~A}), 0.53$ to $1.86(\mathrm{~B}), 0.02$ to $0.04(\mathrm{C}), 0.06$ to $0.16(\mathrm{D})$, and 0.00 to 0.13 (E). 

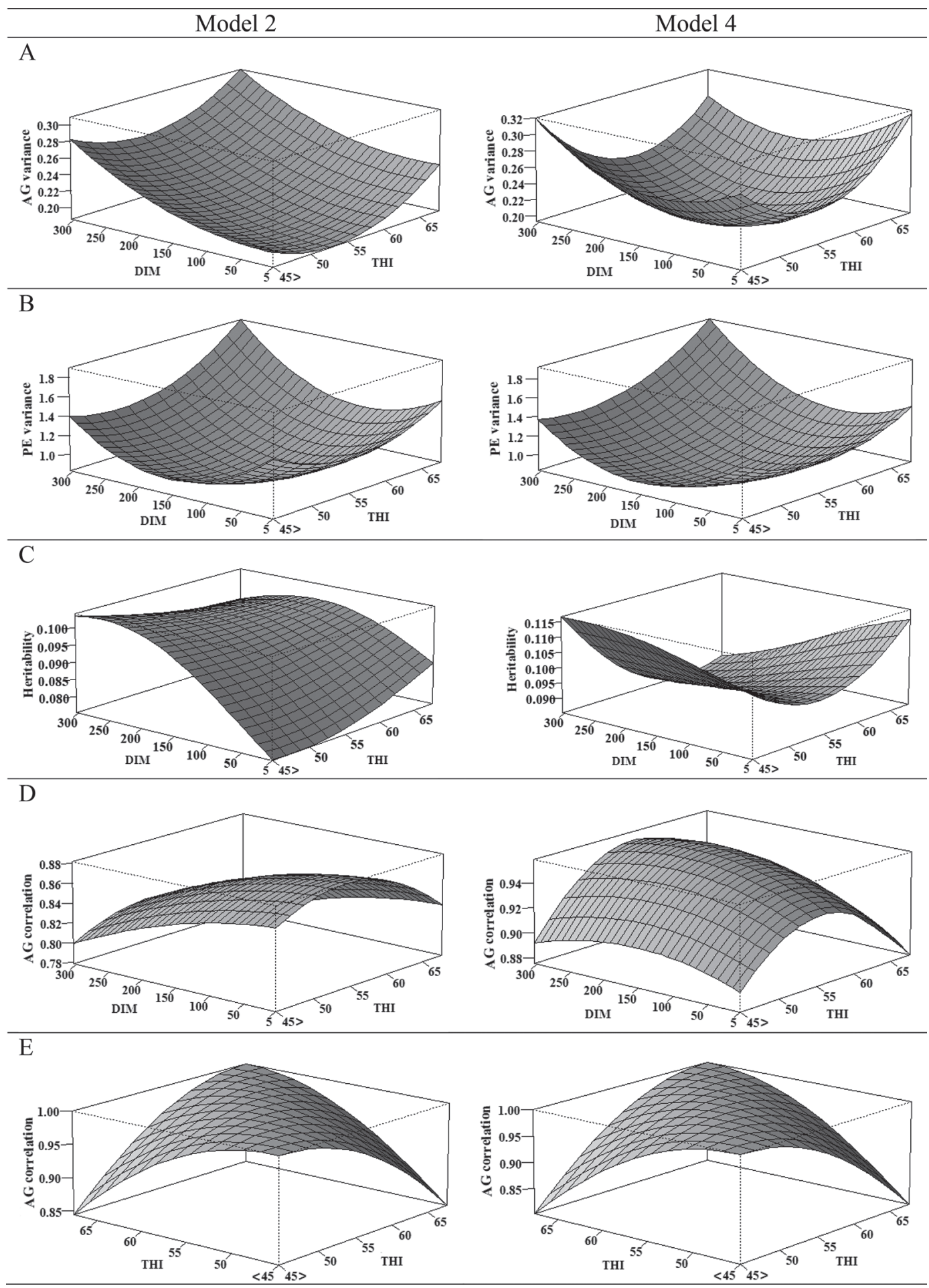

Figure 5. Additive genetic (AG) and permanent environmental (PE) variances, heritabilities, and genetic correlations for SCS estimated with the genomic random regression model 2 and the pedigree-based random regression model 4 (both models considering genotype by environment interactions) for DIM and temperature-humidity index (THI) combinations. Posterior SD for estimates from model 2 ranged from 0.02 to 0.03 (A), 0.02 to 0.06 (B), 0.00 to 0.01 (C), 0.05 to 0.09 (D), and 0.00 to 0.09 (E). Posterior SD for estimates from model 4 ranged from 0.02 to 0.07 (A), 0.02 to 0.08 (B), 0.01 to $0.02(\mathrm{C}), 0.04$ to 0.11 (D), and 0.00 to $0.12(\mathrm{E})$. 

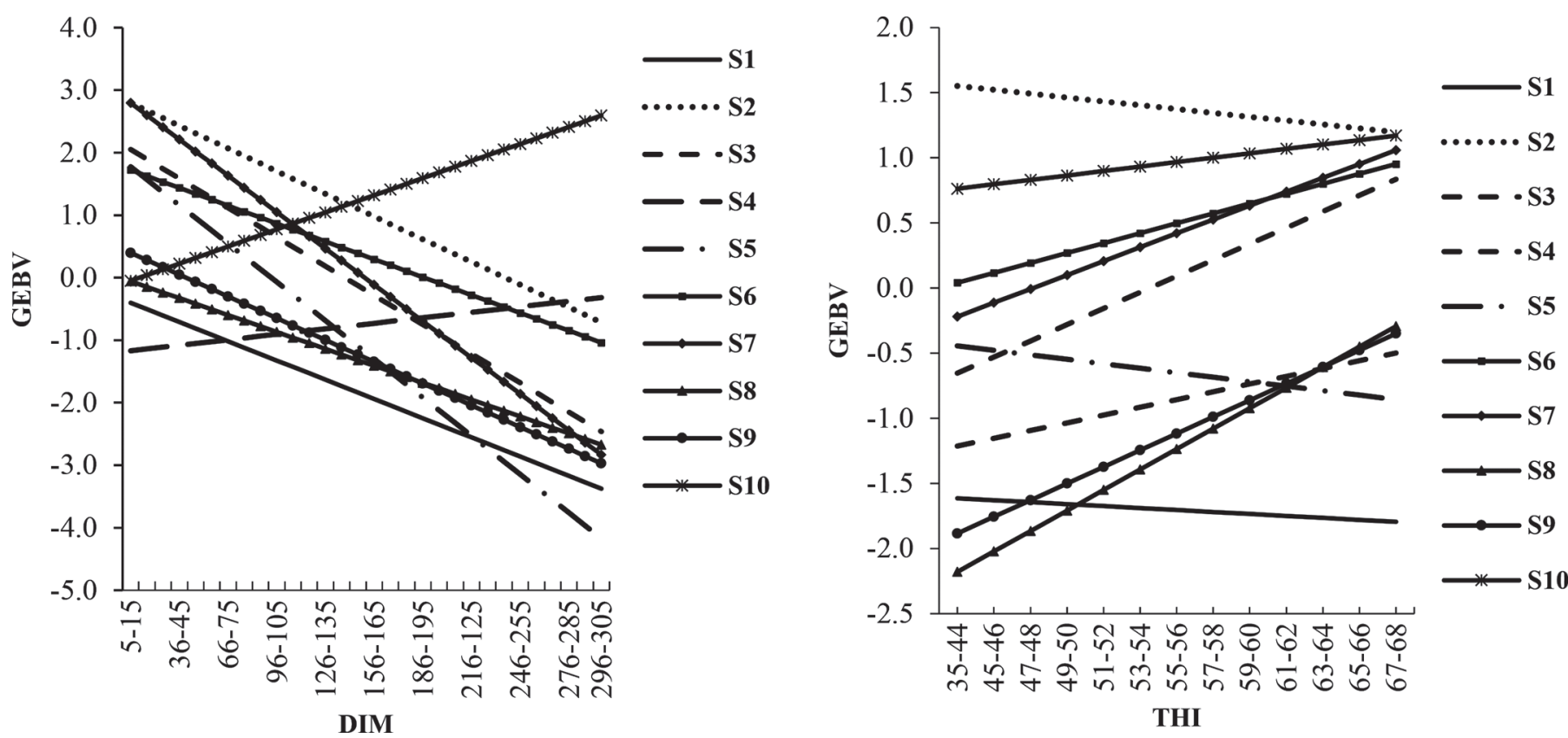

Figure 6. Genomic estimated breeding values (GEBV) for milk yield for 10 genotyped sires (S1-S10) with at least 150 genotyped daughters by DIM and temperature-humidity index (THI) classes.

$\times$ heat stress interaction for SCS. Accordingly, only slight re-rankings of sires according to GEBV across DIM and THI classes (Figure 7) were observed. Similar results were reported from pedigree-based models, aiming on the exploration of environmental sensitivity of SCS. For instance, genetic correlations for SCS were

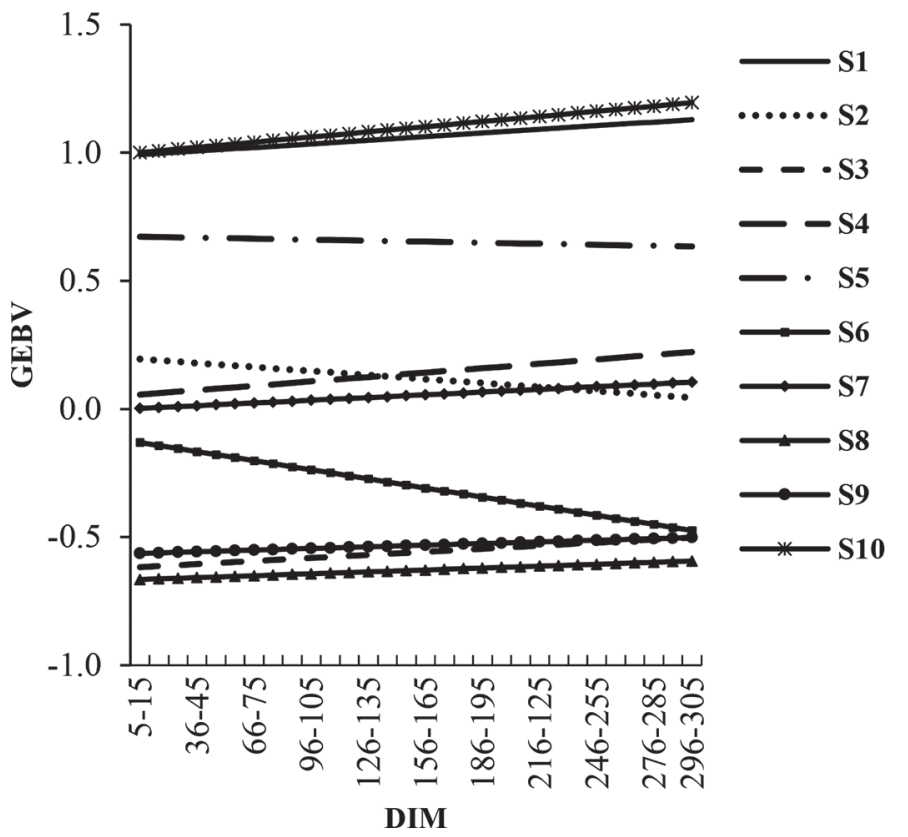

quite large $(>0.80)$ when grouping herds according to herd parameters [e.g., intraherd standard deviations for milk yield (Castillo-Juarez et al., 2000; Raffrenato et al., 2003) or average herd SCS (Banos and Shook, 1990; Calus et al., 2005)]. However, Calus et al. (2006) found considerable re-rankings of sires according to their SCS

Figure 7. Genomic estimated breeding values (GEBV) for SCS for 10 genotyped sires (S1-S10) with at least 150 genotyped daughters by DIM and temperature-humidity index (THI) classes. 
EBV for different combinations of bulk milk SCC levels and DIM.

Genetic correlations between the same traits recorded in different THI classes (i.e., model 2 and model 4) decreased with increasing distances between THI classes (Figure 4E for MY; Figure 5E for SCS). Genetic correlations were smallest between MY at THI $<45$ with MY at THI 67 to 68 (i.e., 0.49 from model 2 and 0.18 from model 4). Genetic correlations for SCS across different THI classes were larger than estimates for MY. The lowest genetic correlation was 0.85 from model 2 and 0.80 from model 4 (Figure 5E). Quite large genetic correlations for SCS across THI classes support the explanations given for the large SCS correlations across DIM $\times$ THI combinations (i.e., less environmental sensitivity for SCS compared with MY). Hence, in agreement with Hayes et al. (2016), we suggest consideration of MY from different THI classes as correlated traits in genetic evaluations for German Holsteins.

\section{Prediction Accuracies}

Models Without $G \times E$ Interactions. Prediction accuracies from the 5-fold cross-validations are listed in Table 2. In general, prediction accuracies were larger for MY compared with SCS. The heritability, a major parameter for the genetic trait architecture, had substantial effect on prediction accuracies (Goddard and Hayes, 2009; Hayes et al., 2009). Given the same size of a reference population, prediction accuracies increased with increasing trait heritabilities (Goddard and Hayes, 2009; Guo et al., 2014; Yao et al., 2017).

In agreement with Yin et al. (2014) and Forneris et al. (2016), replacing $\mathbf{A}$ by $\mathbf{G}$ contributed to an increase of genomic predictions. In our study, consideration of genomic information had substantial effect on prediction accuracies for daughters (i.e., almost a doubling of prediction accuracies). For MY, the prediction accuracy for $\mathrm{GEBV}_{\text {DIM }}$ of sires via model 1 was 0.82 , but the prediction accuracy for the same sires for the conventional $\mathrm{EBV}$ ( $\left.\mathrm{EBV}_{\text {DIM }}\right)$ from model 3 was only 0.72 . For their daughters, the prediction accuracy was 0.79 from model 1 and 0.39 from model 3. Prediction accuracies were lower for SCS than for MY but also increased for SCS when considering genomic information. A significant prediction accuracy increase when considering genomic information was reported for low-heritability traits (Buch et al., 2012).

Models with $G \times E$ Interactions. An increase in prediction accuracies was due to the inclusion of the THI component into statistical modeling and when basing predictions on DIM $\times$ THI combinations (Table 2 ). For only SCS and the pRRM applications, prediction accuracies were slightly larger from model 3 (0.43 for

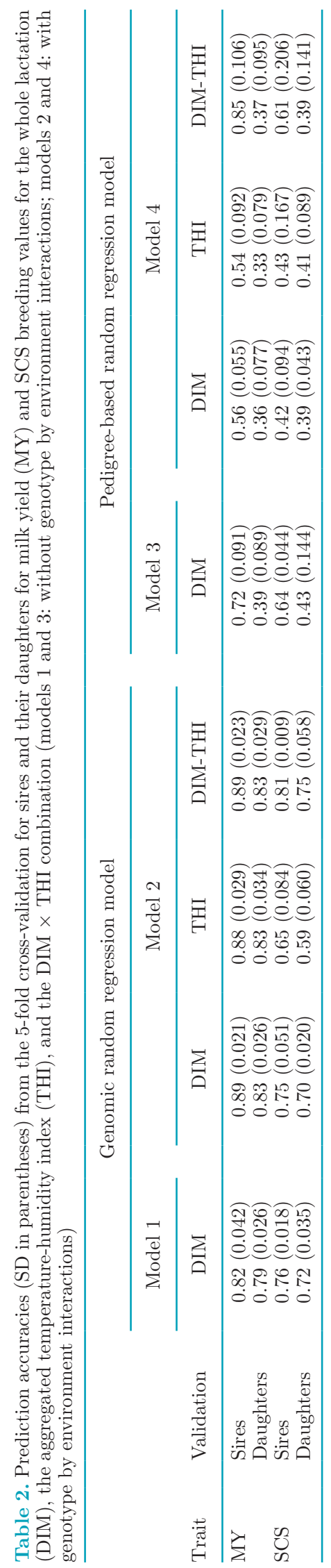


Table 3. Prediction accuracies (SD in parentheses) from the 5-fold cross-validation for sires and their daughters for milk yield (MY) and SCS breeding values for specific DIM and temperature-humidity index (THI) classes, estimated with genomic random regression models

\begin{tabular}{|c|c|c|c|c|c|c|}
\hline Trait & Validation & \multicolumn{3}{|c|}{ DIM } & \multicolumn{2}{|c|}{ THI } \\
\hline MY & Daughters & $0.77(0.045)$ & $0.83(0.026)$ & $0.81(0.027)$ & $0.83(0.025)$ & $0.80(0.039)$ \\
\hline \multirow[t]{2}{*}{ SCS } & Sires & $0.73(0.044)$ & $0.75(0.051)$ & $0.76(0.057)$ & $0.65(0.113)$ & $0.71(0.106)$ \\
\hline & Daughters & $0.67(0.047)$ & $0.69(0.022)$ & $0.70(0.017)$ & $0.59(0.066)$ & $0.60(0.062)$ \\
\hline
\end{tabular}

daughters, 0.64 for sires) than for the combined DIM $\times$ THI effect from model 4 (0.39 for daughters, 0.61 for sires). Somatic cell score seems to be a specific trait in genomic and genetic evaluations for German Holsteins. Despite low heritabilities, SCS is the trait with highest accuracies for GEBV. Yin and König (2018) related genetic parameters to genomic herd descriptors. Also in this study, the genetic (co)variance pattern for SCS differed from those for milk or protein yield.

Regarding the gRRM considering THI (model 2), MY prediction accuracies for $\mathrm{GEBV}_{\mathrm{TH}}$ were 0.88 for sires and 0.83 for their daughters. A slight prediction accuracy increase was due to the GEBV construction considering genomic effects for DIM $\times$ THI classes simultaneously. The prediction accuracy for $\mathrm{GEBV}_{\text {DIM-THI }}$ was 0.89 for sires (plus 0.07 compared with model 1) and 0.83 for their daughters (plus 0.04 compared with model 1). For SCS, prediction accuracies for $\mathrm{GEBV}_{\text {THI }}$ were lower than for $\mathrm{GEBV}_{\text {DIM }}$ (0.65 vs. 0.75 for sires; 0.59 vs. 0.70 for daughters). Regarding genomic models and SCS, prediction accuracies were largest for GEB$\mathrm{V}_{\text {DIM-THI }}$. The gain in prediction accuracy when calculating GEBV $V_{\text {DIM-тнI }}$ instead of GEBV $_{\text {DIM }}$ or instead of $\mathrm{GEBV}_{\text {THI }}$ was larger for SCS compared with MY.

The accuracies of genomic predictions for selected DIM (i.e., prediction accuracies for $\mathrm{GEBV}_{\mathrm{DIM}}$ ) and for specific THI (i.e., prediction accuracies for $\mathrm{GEBV}_{\mathrm{THI}}$ ) are given in Table 3. For both traits MY and SCS, accuracies were larger for the middle and the end of lactation compared with the early-lactation period. In contrast to MY, prediction accuracies for SCS were larger under heat stress (THI 67-68) compared with
THI $<45$, especially for sires. Generally, prediction accuracies of selected DIM $\times$ THI combinations (i.e., prediction accuracies for $\mathrm{GEBV}_{\text {DIM-THI }}$; Table 4) followed the same pattern for results as given in Table 3. For MY, prediction accuracies were throughout larger for THI $<45$, but for SCS and genomic prediction of sires, a light prediction accuracy increase under heat stress conditions (THI 67-68) was observed.

Genomic RRM with a THI gradient allowed the estimation of GEBV $\mathrm{THI}_{\mathrm{THI}}$ and GEBV $\mathrm{CIM}_{\text {DIMI }}$. As a further advantage, prediction accuracies for $\mathrm{GEBV}_{\mathrm{DIM}}$ increased when modeling the THI effect (model 2) compared with a gRRM considering only the time-dependent covariate DIM (model 1). Both types of RRM (i.e., gRRM and pRRM) consider longitudinal data as correlated traits. Information from genetically correlated traits in multitrait genomic models improved genomic predictions over single-trait genomic predictions (Guo et al., 2014; Jiang et al., 2015). In simulations, further increase in prediction accuracy was due to consideration of $\mathrm{G} \times \mathrm{E}$ interaction terms for gRRM (Yin et al., 2014) as well as for multitrait genomic model applications (Bohlouli et al., 2017). As a further advantage, such modeling allows detection of QTL expressions in specific environments (Lillehammer et al., 2007). Tiezzi et al. (2017) considered different environmental descriptors (e.g., herd management, latitude and altitude, geographical region, herd fertility, and meteorological effects) in models with $\mathrm{G} \times \mathrm{E}$ interactions. However, apart from meteorological effects, such $\mathrm{G} \times \mathrm{E}$ modeling only marginally improved genomic prediction accuracies for genotyped bulls. Hence, climate information seems to

Table 4. Prediction accuracies (SD in parentheses) from the 5-fold cross-validation for sires and their daughters for milk yield (MY) and SCS breeding values for combinations of specific DIM and temperature-humidity index (DIM $\times$ THI) classes, estimated with genomic random regression models

\begin{tabular}{|c|c|c|c|c|c|c|c|}
\hline Trait & Validation & \multicolumn{3}{|c|}{ THI $<45$} & \multicolumn{3}{|c|}{ THI 67-68 } \\
\hline MY & Daughters & $0.82(0.017)$ & $0.84(0.024)$ & $0.83(0.025)$ & $0.79(0.035)$ & $0.82(0.035)$ & $0.82(0.026)$ \\
\hline \multirow[t]{2}{*}{ SCS } & Sires & $0.76(0.012)$ & $0.80(0.021)$ & $0.80(0.028)$ & $0.77(0.031)$ & $0.81(0.019)$ & $0.81(0.013)$ \\
\hline & Daughters & $0.71(0.072)$ & $0.74(0.046)$ & $0.76(0.031)$ & $0.69(0.119)$ & $0.72(0.088)$ & $0.75(0.062)$ \\
\hline
\end{tabular}


be a crucial environmental parameter to improve the accuracy of breeding values in genomic evaluations. For both traits, utilization of model 4 instead of model 3 did not improve prediction accuracies. Hence, we suggest consideration of a larger number of phenotypic records to increase prediction accuracies in pRRM with interaction terms (Meseret et al., 2015). An increase of both data sources, phenotypic performances and genomic information for specific DIM and THI classes, allows a target-orientated selection in commercial dairy cattle herds in the context of precision farming. According to Bewley et al. (2015), precision farming contributes to the improvement of cow management strategies to optimize farm economy via utilization of modern technologies. Genetic marker technology allows phenotype prediction of genotyped female calves or heifers (Yin and König, 2016), which can be optimized when considering environmental particularities via $\mathrm{G} \times \mathrm{E}$ interaction models. An increase of SNP markers and test-day records per genotyped animals for a large number of THI classes and the application of $\mathrm{G} \times \mathrm{E}$ interaction models will gradually contribute to improvements of genomic predictions.

\section{CONCLUSIONS}

Genomic RRM considering $\mathrm{G} \times \mathrm{E}$ interactions contributed to an increase of prediction accuracies of breeding values for sires and their daughters. Hence, the availability of a large data set including genotyped cows with longitudinal test-day records for a broad THI range allows genomic predictions for extreme THI classes representing limited phenotypic data. In addition, for genomic models with $\mathrm{G} \times \mathrm{E}$ interactions, posterior standard deviations of genetic (co)variance components were very small. Genetic parameters and prediction accuracies from the gRRM were more accurate than those from the pRRM. As a further disadvantage for the pRRM, heritabilities from the extreme THI classes were inflated. Regarding gRRM applications, some genetic correlations for MY and specific THI $\times$ THI or THI $\times$ DIM combinations were extremely small (e.g., only 0.26 between MY recorded at DIM 5-15 and MY recorded at THI <45). Hence, it is imperative to consider $\mathrm{G} \times \mathrm{E}$ interactions via THI gradients in gRRM for MY. Such a modeling strategy for MY (i.e., simultaneous consideration of DIM and THI) also improved prediction accuracies of GEBV for specific DIM compared with a simpler model just considering the DIM covariate. Nevertheless, regarding practical implementations, we found increasing computation time for a gRRM accounting for $\mathrm{G} \times \mathrm{E}$ interactions ( $26 \mathrm{~d}$ compared with a genomic model without $\mathrm{G} \times \mathrm{E}$ interactions).

\section{ACKNOWLEDGMENTS}

The authors gratefully acknowledge funding from the German Federal Ministry of Education and Research (BMBF) and from the Förderverein Bioökonomieforschung e.V. (FBV)/German Holstein Association (DHV) for the collaborative project "KMU-innovativ-10: KuhL-cow calibration groups for the implementation of selection strategies based on high-density genotyping in dairy cattle," grant no. 031A416C. We also acknowledge funding for M. Bohlouli from the Alexander von Humboldt Foundation (Bonn, Germany).

\section{REFERENCES}

Abdullahpour, R., M. M. Shahrbabak, A. Nejati-Javaremi, R. V. Torshizi, and R. Mrode. 2013. Genetic analysis of milk yield, fat and protein content in Holstein dairy cows in Iran: Legendre polynomials random regression model applied. Arch. Tierzucht 56:497-508.

Aguilar, I., I. Misztal, D. Johnson, A. Legarra, S. Tsuruta, and T. Lawlor. 2010. Hot topic: A unified approach to utilize phenotypic, full pedigree, and genomic information for genetic evaluation of Holstein final score. J. Dairy Sci. 93:743-752.

Banos, G., and G. Shook. 1990. Genotype by environment interaction and genetic correlations among parities for somatic cell count and milk yield. J. Dairy Sci. 73:2563-2573.

Bérénos, C., P. A. Ellis, J. G. Pilkington, and J. M. Pemberton. 2014. Estimating quantitative genetic parameters in wild populations: A comparison of pedigree and genomic approaches. Mol. Ecol. 23:3434-3451.

Bewley, J., R. Russell, K. Dolecheck, and M. Borchers. 2015. Precision dairy monitoring: What have we learned? Pages 33-44 in Precision Livestock Farming Applications: Making Sense of Sensors to Support Farm Management. Wageningen Academic Publishers, Wageningen, the Netherlands.

Bohlouli, M., S. Alijani, A. N. Javaremi, S. König, and T. Yin. 2017. Genomic prediction by considering genotype $\times$ environment interaction using different genomic architectures. Ann. Anim. Sci. 17:683-701.

Bohlouli, M., J. Shodja, S. Alijani, and A. Eghbal. 2013. The relationship between temperature-humidity index and test-day milk yield of Iranian Holstein dairy cattle using random regression model. Livest. Sci. 157:414-420.

Bohmanova, J., I. Misztal, and J. Cole. 2007. Temperature-humidity indices as indicators of milk production losses due to heat stress. J. Dairy Sci. 90:1947-1956.

Bohmanova, J., I. Misztal, S. Tsuruta, H. Norman, and T. Lawlor. 2008. Genotype by environment interaction due to heat stress. J. Dairy Sci. 91:840-846.

Bowman, J. 1972. Genotype $\times$ environment interactions. Ann. Genet. Sel. Anim. 4:117-123.

Brügemann, K., E. Gernand, U. Von Borstel, and S. König. 2011. Genetic analyses of protein yield in dairy cows applying random regression models with time-dependent and temperature $\times$ humidity-dependent covariates. J. Dairy Sci. 94:4129-4139.

Buch, L. H., M. Kargo, P. Berg, J. Lassen, and A. C. Sørensen. 2012. The value of cows in reference populations for genomic selection of new functional traits. Animal 6:880-886.

Calus, M. P., L. Janss, and R. Veerkamp. 2006. Genotype by environment interaction for somatic cell score across bulk milk somatic cell count and days in milk. J. Dairy Sci. 89:4846-4857.

Calus, M. P., J. Windig, and R. Veerkamp. 2005. Associations among descriptors of herd management and phenotypic and genetic levels of health and fertility. J. Dairy Sci. 88:2178-2189.

Carabaño, M. J., B. Logar, J. Bormann, J. Minet, M. L. Vanrobays, C. Díaz, B. Tychon, N. Gengler, and H. Hammami. 2016. Model- 
ing heat stress under different environmental conditions. J. Dairy Sci. 99:3798-3814.

Castillo-Juarez, H., P. Oltenacu, R. Blake, C. McCulloch, and E. Cienfuegos-Rivas. 2000. Effect of herd environment on the genetic and phenotypic relationships among milk yield, conception rate, and somatic cell score in Holstein cattle. J. Dairy Sci. 83:807-814.

de los Campos, G., D. Gianola, and B. Heringstad. 2006. A structural equation model for describing relationships between somatic cell score and milk yield in first-lactation dairy cows. J. Dairy Sci. $89: 4445-4455$.

Falconer, D. S., and T. F. C. Mackay. 1996. Introduction to Quantitative Genetics. 4th ed. Longman Group, Essex, UK.

Forneris, N. S., J. Steibel, A. Legarra, Z. Vitezica, R. Bates, C. Ernst, A. Basso, and R. Cantet. 2016. A comparison of methods to estimate genomic relationships using pedigree and markers in livestock populations. J. Anim. Breed. Genet. 133:452-462.

Fujii, C., and M. Suzuki. 2006. Comparison of homogeneity and heterogeneity of residual variance using random regression test-day models for first lactation Japanese Holstein cows. Anim. Sci. J. $77: 28-32$.

Goddard, M. E., and B. J. Hayes. 2009. Mapping genes for complex traits in domestic animals and their use in breeding programmes. Nat. Rev. Genet. 10:381-391.

Guo, G., F. Zhao, Y. Wang, Y. Zhang, L. Du, and G. Su. 2014. Comparison of single-trait and multiple-trait genomic prediction models. BMC Genet. 15:30.

Haile-Mariam, M., J. Pryce, C. Schrooten, and B. Hayes. 2015. Including overseas performance information in genomic evaluations of Australian dairy cattle. J. Dairy Sci. 98:3443-3459.

Hammami, H., J. Bormann, N. M'hamdi, H. H. Montaldo, and N. Gengler. 2013. Evaluation of heat stress effects on production traits and somatic cell score of Holsteins in a temperate environment. J. Dairy Sci. 96:1844-1855.

Hammami, H., B. Rekik, C. Bastin, H. Soyeurt, J. Bormann, J. Stoll, and N. Gengler. 2009. Environmental sensitivity for milk yield in Luxembourg and Tunisian Holsteins by herd management level. J. Dairy Sci. 92:4604-4612.

Hammami, H., J. Vandenplas, M.-L. Vanrobays, B. Rekik, C. Bastin, and N. Gengler. 2015. Genetic analysis of heat stress effects on yield traits, udder health, and fatty acids of Walloon Holstein cows. J. Dairy Sci. 98:4956-4968.

Hayes, B. J., P. J. Bowman, A. Chamberlain, and M. Goddard. 2009. Invited review: Genomic selection in dairy cattle: Progress and challenges. J. Dairy Sci. 92:433-443.

Hayes, B. J., H. D. Daetwyler, and M. E. Goddard. 2016. Models for genome $\times$ environment interaction: Examples in livestock. Crop Sci. 56:2251-2259.

Hijmans, R. J., E. Williams, C. Vennes, and M. R. J. Hijmans. 2016. Package 'geosphere'. Accessed Nov. 19, 2017. https://cran.r -project.org/web/packages/geosphere/index.html.

Jamrozik, J., J. Bohmanova, and L. Schaeffer. 2010. Relationships between milk yield and somatic cell score in Canadian Holsteins from simultaneous and recursive random regression models. J. Dairy Sci. 93:1216-1233.

Jiang, J., Q. Zhang, L. Ma, J. Li, Z. Wang, and J. Liu. 2015. Joint prediction of multiple quantitative traits using a Bayesian multivariate antedependence model. Heredity 115:29-36.

König, S., G. Dietl, I. Raeder, and H. Swalve. 2005. Genetic relationships for dairy performance between large-scale and small-scale farm conditions. J. Dairy Sci. 88:4087-4096.

Lee, S. H., M. E. Goddard, P. M. Visscher, and J. H. van der Werf. 2010. Using the realized relationship matrix to disentangle confounding factors for the estimation of genetic variance components of complex traits. Genet. Sel. Evol. 42:22.

Lillehammer, M., J. Ødegård, and T. H. E. Meuwissen. 2007. Random regression models for detection of gene by environment interaction. Genet. Sel. Evol. 39:105.

Lillehammer, M., J. Ødegård, and T. H. E. Meuwissen. 2009. Reducing the bias of estimates of genotype by environment interactions in random regression sire models. Genet. Sel. Evol. 41:30.
Macciotta, N. P., S. Biffani, U. Bernabucci, N. Lacetera, A. Vitali, P. Ajmone-Marsan, and A. Nardone. 2017. Derivation and genomewide association study of a principal component-based measure of heat tolerance in dairy cattle. J. Dairy Sci. 100:4683-4697.

Martins, A. M., A. Silvestre, M. Petim-Batista, and J. Colaço. 2011. Somatic cell score genetic parameter estimates of dairy cattle in Portugal using fractional polynomials. J. Anim. Sci. 89:1281-1285.

Meseret, S., B. Tamir, G. Gebreyohannes, M. Lidauer, and E. Negussie. 2015. Genetic analysis of milk yield in first-lactation Holstein Friesian in Ethiopia: A lactation average vs random regression test-day model analysis. Asian-australas. J. Anim. Sci. 28:1226-1234.

Misztal, I., S. Tsuruta, T. Strabel, B. Auvray, T. Druet, and D. Lee. 2002. BLUPF90 and related programs. Communication no. 28-07. Pages 743-744 in Proc. 7th World Congress for the Genetic Applied Livestock Production, Montpellier, France.

Momen, M., A. A. Mehrgardi, A. Sheikhy, A. Esmailizadeh, M. A. Fozi, A. Kranis, B. D. Valente, G. J. Rosa, and D. Gianola. 2017. A predictive assessment of genetic correlations between traits in chickens using markers. Genet. Sel. Evol. 49:16.

Naderi, S., M. Bohlouli, T. Yin, and S. König. 2018. Genomic breeding values, SNP effects and gene identification for disease traits in cow training sets. Anim. Genet. 49:178-192.

Nguyen, T. T., P. J. Bowman, M. Haile-Mariam, J. E. Pryce, and B. J. Hayes. 2016. Genomic selection for tolerance to heat stress in Australian dairy cattle. J. Dairy Sci. 99:2849-2862.

Nguyen, T. T., J. B. Garner, P. J. Bowman, M. Haile-Mariam, B. J. Hayes, and J. E. Pryce. 2018. Breeding for heat tolerance in Australian dairy cattle: From development to implementation. In Proc. World Congress on Genetics Applied to Livestock Production. Accessed May 8, 2018. http://www.wcgalp.org/proceedings/ 2018/breeding-heat-tolerance-australian-dairy-cattle-development -implementation.

Nishiura, A., O. Sasaki, M. Aihara, H. Takeda, and M. Satoh. 2015. Genetic analysis of fat-to-protein ratio, milk yield and somatic cell score of Holstein cows in Japan in the first three lactations by using a random regression model. Anim. Sci. J. 86:961-969.

NRC. 1971. A Guide to Environmental Research on Animals. Natl. Acad. Sci., Washington, DC.

Ovenden, B., A. Milgate, L. J. Wade, G. J. Rebetzke, and J. B. Holland. 2018. Accounting for genotype-by-environment interactions and residual genetic variation in genomic selection for water-soluble carbohydrate concentration in wheat. G3 (Bethesda) 8:1909 1919.

Powell, J. E., P. M. Visscher, and M. E. Goddard. 2010. Reconciling the analysis of IBD and IBS in complex trait studies. Nat. Rev. Genet. 11:800-805.

Raffrenato, E., R. Blake, P. Oltenacu, J. Carvalheira, and G. Licitra. 2003. Genotype by environment interaction for yield and somatic cell score with alternative environmental definitions. J. Dairy Sci. 86:2470-2479.

Ravagnolo, O., and I. Misztal. 2000. Genetic component of heat stress in dairy cattle, parameter estimation. J. Dairy Sci. 83:2126-2130.

Reents, R. 2014. Aktuelle Entwicklungen zur genomischen Selektion. 7. Pferdeworkshop Uelzen. Accessed May 8, 2018. http:// equinephenotypes.org/DivDok/PWSUelzen2014A_RREENTS _GenomischeSelektion_20140219.pdf.

Robertson, A. 1959. The sampling variance of the genetic correlation coefficient. Biometrics 15:469-485.

Santana, M., A. Bignardi, R. Pereira, G. Stefani, and L. El Faro. 2017. Genetics of heat tolerance for milk yield and quality in Holsteins. Animal 11:4-14.

Schierenbeck, S., F. Reinhardt, R. Reents, H. Simianer, and S. König. 2011. Identification of informative cooperator herds for progeny testing based on yield deviations. J. Dairy Sci. 94:2071-2082.

Segelke, D., J. Chen, Z. Liu, F. Reinhardt, G. Thaller, and R. Reents. 2012. Reliability of genomic prediction for German Holsteins using imputed genotypes from low-density chips. J. Dairy Sci. 95:54035411.

Snelling, W., L. Kuehn, R. Thallman, J. Keele, and G. Bennett. 2009. Genomic heritability of beef cattle growth. J. Anim. Sci. 87(ESuppl. 2):396. (Abstr.) 
Strabel, T., J. Szyda, E. Ptak, and J. Jamrozik. 2005. Comparison of random regression test-day models for Polish Black and White cattle. J. Dairy Sci. 88:3688-3699.

Tiezzi, F., G. de Los Campos, K. P. Gaddis, and C. Maltecca. 2017. Genotype by environment (climate) interaction improves genomic prediction for production traits in US Holstein cattle. J. Dairy Sci. 100:2042-2056.

VanRaden, P. M. 2008. Efficient methods to compute genomic predictions. J. Dairy Sci. 91:4414-4423.

Veerkamp, R. F., H. Mulder, R. Thompson, and M. Calus. 2011. Genomic and pedigree-based genetic parameters for scarcely recorded traits when some animals are genotyped. J. Dairy Sci. 94:41894197.

Wiggans, G. R., T. Sonstegard, P. VanRaden, L. Matukumalli, R. Schnabel, J. Taylor, F. Schenkel, and C. Van Tassell. 2009. Selection of single-nucleotide polymorphisms and quality of genotypes used in genomic evaluation of dairy cattle in the United States and Canada. J. Dairy Sci. 92:3431-3436.

Yao, C., G. De Los Campos, M. VandeHaar, D. Spurlock, L. Armentano, M. Coffey, Y. De Haas, R. Veerkamp, C. Staples, and E.
Connor. 2017. Use of genotype $\times$ environment interaction model to accommodate genetic heterogeneity for residual feed intake, dry matter intake, net energy in milk, and metabolic body weight in dairy cattle. J. Dairy Sci. 100:2007-2016.

Yin, T., and S. König. 2016. Genomics for phenotype prediction and management purposes. Anim. Front. 6:65-72.

Yin, T., and S. König. 2018. Heritabilities and genetic correlations in the same traits across different strata of herds created according to continuous genomic, genetic, and phenotypic descriptors. J. Dairy Sci. 101:2171-2186.

Yin, T., E. Pimentel, U. K. v. Borstel, and S. König. 2014. Strategy for the simulation and analysis of longitudinal phenotypic and genomic data in the context of a temperature $\times$ humidity-dependent covariate. J. Dairy Sci. 97:2444-2454.

Zavadilová, L., J. Jamrozik, and L. Schaeffer. 2005. Genetic parameters for test-day model with random regressions for production traits of Czech Holstein cattle. Czech J. Anim. Sci. 50:142-154.

Zwald, N. R., K. Weigel, W. Fikse, and R. Rekaya. 2003. Application of a multiple-trait herd cluster model for genetic evaluation of dairy sires from seventeen countries. J. Dairy Sci. 86:376-382. 